\title{
RECURSIVE REALIZATION OF 2-D LINEAR SYSTEMS
}

\author{
(Presented by N. Alumäe)
}

\section{Introduction}

In recent years, several authors have discussed the two-dimensional (2-D) realization problems of the 2-D input-output description by different 2 -D state space models in a variety of situations. The input-output description have been expressed in terms of 2-D Markov parameters $\left[{ }^{1-3}\right]$, or in terms of 2-D transfer function $\left[{ }^{4-10}\right]$. For a general 2-D system, at this moment there is no technique available for constructing minimal realizations $\left[{ }^{11}\right]$. For the important special case of 2-D system : with separable denominator transfer function, $T$. Hinamoto $\left[{ }^{1,2}\right]$ has presented the algorithms for complete and partial minimal reaization 3 from the given set of 2-D Markov parameters; the Roesser's model is used to represent the system. T. Hinamoto and F. W. Fairman $\left[{ }^{3}\right]$ have treated the canonical minimal partila realization problem in the same situation.

In this paper, we also consider the partial minimal realization problem for systems with separable denominator transfer function. Unlike $\left[{ }^{1-3}\right]$ we do not look for a solution for some fixed $\mathrm{N}(\mathrm{N}$ is the number of given 2-D Markov parameters), but look for a recursive solution whero each extension of the sequence of 2-D Markov parameters can be met by calculating just a few new elements in the corresponding realization. Our approach here is an extension of the method proposed by $\mathrm{J}$. Rissanen for the $1-D$ case $\left[{ }^{12}\right]$.

\section{Problem statement}

Consider the Roesser's state space model of the 2-D system with separable denominator transfer function abbreviated by $\Sigma(n, m)=\left(A_{1}, A_{3}\right.$, $\left.A_{4}, b_{1}, b_{2}, c_{1}, c_{2}\right)\left[{ }^{1}\right]:$

$$
\begin{aligned}
& x^{h}(i+1, j)=A_{1} x^{h}(i, j)+b_{1} u(i, j), \\
& x^{v}(i, j+1)=A_{3} x^{h}(i, j)+A_{4} x^{v}(i, j)+b_{2} u(i, j), \\
& y(i, j)=c_{1} x^{h}(i, j)+c_{2} x^{v}(i, j), i, j \geqslant 0,
\end{aligned}
$$

where $x^{h}(i, j)$ is an $n$ dimensional horisontal state vector, $x^{v}(i, j)$ is an $m$ dimensional vertical state vector, $u(i, j)$ is a scalar input, $y(i, j)$ is a scalar output, and $A_{1}, A_{3}, A_{4}, b_{1}, b_{2}, c_{1}, c_{2}$ are real matrices of appropriate dimensions. For the system (1), the set of boundary conditions consists of $x^{h}(0, j)$, for $j \geqslant 0$ and $x^{v}(i, 0)$ for $i \geqslant 0$.

If the boundary conditions are equal to zero and an impulse is applied as an input $(u(0,0)=1,(u(i, j)=0$ in other cases $)$, then the impulse response of the system (1) is $\left[{ }^{1}\right]$ 


$$
\begin{aligned}
& y(i, 0)=c_{1} A_{1}^{i-1} b_{1} \triangleq w_{i 0}, \quad y(0, j)=c_{2} A_{4}^{j-1} b_{2} \triangleq w_{0 j}, \\
& y(i, j)=c_{2} A_{4}^{j-1} A_{3} A_{1}^{i-1} b_{1} \triangleq w_{i j}, \quad i>0, \quad j>0 .
\end{aligned}
$$

The real numbers $w_{i j}$ are also called the 2-D Markov parameters of the system (1). Let us define an $2 k+1$ dimensional vector $W_{k}$ as

$$
W_{k}\left(w_{k 0}, w_{k 1}, \ldots, w_{k k}, w_{k-1}, \ldots, w_{1 k}, w_{0 k}\right), \quad k=1,2, \ldots .
$$

The partial realization problem can be defined as follows $\left[{ }^{1}\right]$. Given the finite sequence $\left\{W_{k} ; k=1,2, \ldots, N\right\}$, system (1) is said to be a partial realization of that sequence if and only if the Markov parameters formed from the realized system match the given set of Markov parameters contained in the sequence. Furthermore, the realization is said to be a minimal partial realization if and only if $n$ and $m$ are minimal among all other partial realizations.

In this paper we consider the following more general variant of the minimal partial realization problem. Let $\Sigma_{N^{\prime}}$ denote.a minimal partial realization by Roesser's state space model of the sequence $\left\{W_{k} ; k=1\right.$, $\left.\ldots, N^{\prime}\right\}$, Given the sequence $\left\{W_{k} ; k=1, \ldots, N\right\}$, find a sequence of minimal partial realization $\left\{\Sigma_{N^{\prime}}, N^{\prime}=1,2, \ldots, N\right\}$ such that $\Sigma_{N^{\prime}} \subseteq$ $\sum_{N^{\prime \prime}}$, if $N^{\prime}<N^{\prime \prime}$. Here the inclusion symbol means that the matrices in $\sum_{N^{\prime}}$ appear as submatrices of the corresponding ones in $\Sigma_{N^{\prime \prime}}$.

\section{Generalized Hankel matrices and their factorization}

In this section we describe two matrices introduced in $\left[{ }^{1}\right]$, which play, in the case of 2-D systems, a role similar to the one of the Hankel matrix in the 1-D realization problem. These matrices are given as follows:

$$
\begin{aligned}
& H_{L, n+1}^{(s)}=\left\|h_{i+j-1}^{(s)}\right\|, \quad i=1, \ldots, L, \quad j=1, \ldots, n+1, \\
& V_{m+1, J}^{(t)}=\left\|v_{i+j-1}^{(t)}\right\|, \quad i=1, \ldots, m+1, \quad j=1, \ldots, J,
\end{aligned}
$$

where

$$
\begin{aligned}
& h_{i}^{(s)}=\left(w_{i 0}, w_{i 1}, \ldots ; w_{i s}\right)^{\mathrm{T}}, \quad i=1,2, \ldots, \\
& v_{i}^{(t)}=\left(w_{0 i}, w_{1 i}, \ldots, w_{t i}\right), \quad i=1,2, \ldots .
\end{aligned}
$$

The former is called the horizontal Hankel matrix and the latter is called the vertical Hankel matrix.

The recursive realization algorithm, proposed in this paper, is based on the following types of factorizations of the horizontal and vertical Hankel matrices

$$
H_{L, n+1}^{(s)}=S(L, n+1) R(n+1) ; \quad L \geqslant n+1, \quad \text { rank } \quad H_{L, n+1}^{(s)} \geqslant n
$$

and

$$
V_{m+1, J}^{(t)}=P(m+1) Q(m+1, J), \quad J \geqslant m+1, \quad \text { rank } \quad V_{m+1, J}^{(t)} \geqslant m .
$$

Here $R(n+1)$ is upper triangular with 1 's on the main diagonal and $P(m+1)$ is lower triangular with '1's on the main diagonal. These factors are not unique. By setting certain elements of $S(L, n+1)$ and $Q(m+1, J)$ equal to zero, we shall be able to calculate the elements of factors one 
by one and, moreover, an addition of rows and columns to $H_{L, n+1}^{(s)}$ and $V_{m+1, J}^{(t)}$ will not change the elements already calculated.

A 1 gorith $\mathrm{m}$ 1. Factorization of horizontal Hankel matrix.

Step 1. Set the first column in $S(L, n+1)$ equal to that of $H_{L, n+1}^{(s)}$.

Step 2. Recursively, at the $k+1$ th step all the $s_{i j}$ (eiements of $S(L, n+1)$ ) and $r_{i j}$ (elements of $R(n+1)$ ) for $j=1, \ldots, k$ have been determined. Suppose, first, that the $k$ th column of $S(L, n+1)$ is not zero. Let $q(k)$ be the least integer such that $s_{q(k), k} \neq 0$. Set $s_{q(k)+i, p}=0$ for $p>k, i=0, \ldots, s$. Equation (2) leads to a set of $k$ equations one for each row $q(j), j=1, \ldots, k$. From these the unknowns $r_{1, k+1}, \ldots, r_{h, h+1}$ can be found one by one. These determine the $k+1$ th column of $S(L, n+1)$.

Suppose, next, that the $k$ th column of $S(L, n+1)$ is zero. In this case set the nondiagonal elements in the $k+1$ th column of $\mathrm{R}(n+1)$ to arbitrary. values, say, to zero.

A 1 gor ithm 2. Factorization of vertical Hankel matrix.

Step 1. Set the first row in $Q(m+1, J)$ equal to that of $V_{m+1, J}^{(t)}$.

Step 2. Recursively, at the $k+1$ th step all the $q_{i j}$ (elements of $\left.Q(m+1, J)\right)$ and $p_{i j}$ (elements of $\left.P(m+1)\right)$ for $i=1, \ldots, k$ have been determined. Suppose, first, that the $k$ th row of $Q(m+1, J)$ is not zero. Let $s(k)$ be the least integer such that $q_{k, s(k)} \neq 0$. Set $q_{p, s(k)+i}=0$ for $p>k, i=0,1, \ldots, s$. Equation (3) leads to a set of $k$ equations one for each column $s(j), j=1, \ldots, k$. From these the unknowns $p_{k+1,1}, \ldots$, $p_{k+1, k}$ can be found one by one. These determine the $k+1$ th row of $Q(m+1, J)$.

Suppose, next, that the $k$-th row is zero. In this case set the nondiagonal elements of the $k+1$ th row of $P(m+1)$ to arbitrary values, say, to zero.

\section{Preliminary results}

Let us define

$$
A_{1}(n)=R^{*}(n) R^{-1}(n),
$$

where $R^{*}(n)$ is formed from $R(n+1)$ by omitting the first column and last row,

$$
\begin{aligned}
b_{1}^{T}(n) & =\left[\begin{array}{llll}
1 & 0 & \ldots & 0
\end{array}\right], \\
c_{1}(n) & =\left[\begin{array}{lll}
s_{11} & \ldots & s_{1 n}
\end{array}\right], \\
A_{4}(m) & =P^{-1}(m) P^{*}(m),
\end{aligned}
$$

where $P^{*}(m)$ is formed from $P(m+1)$ by omitting the first row and the last column,

where

$$
\begin{aligned}
& b_{2}^{T}(m)=\left[\begin{array}{lll}
q_{11} & \ldots & q_{m 1}
\end{array}\right], \\
& c_{2}(m)=\left[\begin{array}{llll}
1 & 0 & \ldots & 0
\end{array}\right], \\
& A_{3}(m, n)=\mathcal{O}^{-1}(m) W_{n m}^{T} \mathrm{C}^{-1}(n),
\end{aligned}
$$

$$
\begin{aligned}
\mathcal{O}^{\prime}(m) & =\left[\begin{array}{ll}
c_{2}^{T}(m), A_{4}^{T}(m) & c_{2}^{T}(m), \ldots,\left(A_{4}^{m-1}(m)\right)^{T} C_{2}^{T}(m)
\end{array}\right]^{\mathrm{T}}, \\
\mathcal{C}(n) & =\left[b_{1}(n) ; A_{1}(n) b_{1}(n), \ldots, A_{1}^{n-1}(n) b_{1}(n)\right], \\
W_{n m} & =\left\|w_{k l}\right\|, \quad k=1, \ldots, n, \quad l=1, \ldots, m .
\end{aligned}
$$


Now without proof being too long to present, we shall give a theorem on which the realization algorithm is based.

Theorem. Given $W_{k}, k=1,2, \ldots$, let the rank of the matrix $H_{n, n}^{(2 n-1)}$ be $n$ and $L$ any integer such that $H_{L, n+1}^{(L+n)}$ has rank $n\left(n+1 \leqslant L \leqslant L_{1}\right)$; let the rank of the matrix $V_{m, m}^{(2 m-1)}$ be $n$ and $J$ any integer such that $V_{m+1, J}^{(m+J)}$ has rank $m\left(m+1 \leqslant J \leqslant J_{1}\right)$. Then $\Sigma(n, m)=\left[A_{1}(n), A_{3}(m, n), A_{4}(m), b_{1}(n)\right.$, $\left.b_{2}(m), c_{1}(n), c_{2}(m)\right]$ is a minimal realization of the sequence $\left\{W_{1}, \ldots\right.$ $\left.\ldots, W_{T}\right\}$, where $T \in\left[2 n+1, L_{1}+n\right] \cap\left[2 m+1, J_{1}+m\right]$.

Observe that the matrices (4), (7) and (10) can be computed recursively due to their special form. The following holds

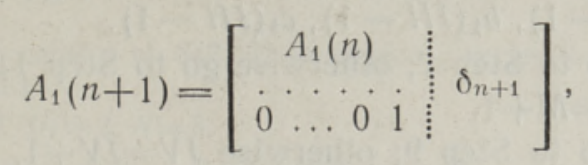

where

$$
\begin{aligned}
& \delta_{n+1}=\left[\begin{array}{ll:l}
-r_{n+1}^{T} & A_{1}^{T}(n) & r_{n, n+1}
\end{array}\right]+r_{n+2}^{T}, \\
& r_{n+i}^{T}=\left[\begin{array}{llll}
r_{1, n+i} & \ldots & r_{n+i-1, n+i}
\end{array}\right], i=1,2 ; \\
& A_{4}(m+1)=\left|\begin{array}{rr} 
& 0 \\
A_{4}(m) & \\
& \\
& 0 \\
& 1 \\
\gamma_{m+1} & \cdots
\end{array}\right|,
\end{aligned}
$$

where

$$
\begin{gathered}
\gamma_{m+1}=\left[\begin{array}{lll}
-p_{m+1} A_{4}(m) & p_{m+1, m}
\end{array}\right]+p_{m+2}, \\
p_{m+i}=\left[\begin{array}{ll}
p_{m+i, 1} \ldots & p_{m+i, m+i-1}
\end{array}\right], i=1,2 \\
A_{3}(m+1 ; n)=\left[\begin{array}{cc}
A_{3}(m, n) \\
\left(\alpha_{m+1}\right. & \left.W_{m n}+w_{m+1}\right) \mathcal{C}^{-1}(n)
\end{array}\right]
\end{gathered}
$$

where

$$
\begin{aligned}
\alpha_{m+1} & =-c_{2}(m+1) A_{4}^{m}(m+1) I(m+1, m) \mathcal{O}^{-1}(m), \\
w_{m+1} & =w_{1, m+1} \ldots w_{n, m+1},
\end{aligned}
$$

and $I(m+1, m)$ is the $m+1$-dimensional unit matrix where the last column is omitted;

$$
A_{3}(m, n+1)=\left[A_{3}(m, n): \mathcal{O}^{-1}(m)\left(W_{m n} \beta_{n+1}+w_{n+1}\right)\right],
$$

where

$$
\begin{aligned}
& \beta_{n+1}=-\mathrm{C}^{-1}(n) I(n, n+1) A_{1}^{n}(n+1) b_{1}(n+1), \\
& w_{n+1}=\left[w_{n+1,1}, \ldots, w_{n+1, m}\right]^{\mathrm{T}}
\end{aligned}
$$

and $I(n, n+1)$ is the $n+1$-dimensional unit matrix where the last row is omitled. 


\section{Realization algorithm}

Step 1. Pick the least $K$ such that $h_{K}^{(2 K+1)} \neq 0$. Set $N=2 K-1, I H=J H=$ $=K$. Pick the least $L$ such that $v_{L}^{(2 L+1)} \neq 0$. Set $M=2 L-1, I V=J V=L$, $I N D=1$.

Step 2. $J H=J H+1, N=N+1$.

Step 3. If $J H \leqslant I H$, go to Step 4; otherwise $I H=I H+1, N=N+1$, go to Step 4.

Step 4. Apply the factorization algorithm 1 on $H_{I H, J H}^{(N)}$.

Step 5. If the last column of $S(I H, J H)$ is nonzero, go to Step 2; otherwise calculate $A_{1}(J H-1), b_{1}(J H-1) ; c_{1}(J H-1)$.

Step 6. If $I N D=1$, go to Step 7; otherwise go to Step 11 .

Step 7. $I V=I V+1, M=M+1$.

Step 8. If $I V \leqslant J V$, go to Step 9 ; otherwise $J V=J V+1, M=M+1$, go to Step 9.

Step 9. Apply the factorization algorithm 2 on $V_{I V, J V}^{(M)}$.

Step 10. If the last row of $Q(I V, J V)$ is nonzero, go Step 7; otherwise calculate $A_{4}(I V-1), b_{2}(I V-1), c_{2}(I V-1)$.

Step 11. If $N<M$, then $I H=I H+1, N=N+1$, apply the factorization algorithm 1 on $H_{I H, J H}^{(N)}$, go to Step 12 ; If $N>M$, then $J V=J V+1, M=$ $=M+1$, apply the factorization algorithm 2 on $V_{I V, J V}^{(M)}$, go to Step 13 ; If $N=M$, then calculate $A_{3}(I V-1, J H-1)$, go to Step 14 .

Step 12. If the last column of $S(I H, J H)$ is zero, go to Step 11; otherwise $I N D=0$, go to Step 2 .

Step 13. If the last row of $Q(I V, J V)$ is zero, go to Step 11; otherwise go to Step 7.

Step 14. Print $N(=M), A_{1}, A_{3}, A_{4}, b_{1}, b_{2}, c_{1}, c_{2}$. If you want to continue, then $I H=I H+1, N=N+1$, apply the factorization algorithm 1 on $H_{I H, J H}^{(N)}$, go to Step 15; otherwise go to Step 17.

Step 15. If the last column of $S(I H, J H)$ is nonzero, then $I N D=0$ go to Step 2 ; otherwise $J V=J V+1, M=M+1$, apply the factorization algorithm 2 on $V_{I V, J V}^{(M)}$.

Step. 16. If the last row of $Q(I V, J V)$ is nonzero, go to Step 7; otherwise go to Step 14.

Step 17. Stop.

$\mathrm{Re} \mathrm{m}$ a r k 1. In this algorithm each time the factorization algorithm $1(2)$ is called, only one additional column (row) is calculated.

R e m a r k 2. The matrices $A_{1}, A_{3}, A_{4}$ are calculated from the formulas (4), (10), (7) or once calculated, are recursiverly updated by formulas (11)-(14)

\section{Numerical example}

Suppose the given sequence $\left\{W_{k} ; k=1,2, \ldots .5\right\}$ is specified as

$W_{1}=\left(\begin{array}{lll}8 & 4 & 4\end{array}\right)$;

$W_{2}=\left(\begin{array}{lllll}4 & 2 & 1 & 2 & 2\end{array}\right) ;$

$W_{3}=\left(\begin{array}{lllllll}4 & 2 & 1 & 0,5 & 0,5 & 1 & 1\end{array}\right)$;

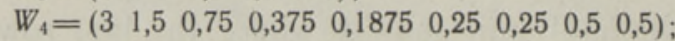

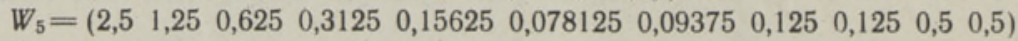

Step 1. $K=1, N=1, I H=J H=1, L=1, M=1, I V=J V=1, I N D=1$.

Step 2. $J H=2, \quad N=2$. 
Step 3. As $J H>I H, I H=2, N=3$.

Step 4. Applying the factorization algorithm 1 on $H_{2,2}^{(3)}$ gives

$$
\left|\begin{array}{lll}
8 & 4 \\
4 & 2 \\
2 & 1 \\
1 & 0,5 \\
4 & \cdots & 4 \\
2 & 2 \\
1 & 1 \\
0,5 & 0,5
\end{array}\right|=\left.\left|\begin{array}{lll}
8 & 0 \\
4 & & 0 \\
2 & 0 \\
1 & 0 \\
\hdashline 4 & 2 \\
2 & \vdots \\
1 & 0,5 \\
0,5 & 0,25
\end{array}\right|\right|^{1} \quad \begin{aligned}
& \\
& 1
\end{aligned} \mid
$$

Step 5. As the last column of $S(2,2)$ is nonzero, we go to Step 2 . Step 2. $J H=3, N=4$.

Step 3. As $J H>I H, I H=3, N=5$.

Step 4. Applying the factorization algorithm 1 on $H_{3,3}^{(5)}$ gives

$\left|\begin{array}{lll}8 & 4 & 4 \\ 4 & 2 & 2 \\ 2 & 1 & 1 \\ 1 & 0,5 & 0,5 \\ 0,5 & 0,25 & 0,25 \\ 0,25 & 0,125 & 0,125 \\ \cdots & \cdots \\ 4 & 4 & 3 \\ 2 & 2 & 1,5 \\ 1 & 1 & 0,75 \\ 0,5 & 0,5 & 0,375 \\ 0,25 & 0,25 & 0,1875 \\ 0,125 & 0,125 & 0,09375 \\ \cdots & \cdots \\ 4 & 3 & 2,5 \\ 2 & 1,5 & 1,25 \\ 1 & 0,75 & 0,625 \\ 0,5 & 0,375 & 0,3125 \\ 0,25 & 0,1875 & 0,15625 \\ 0,125 & 0,09375 & 0,078125\end{array}\right| \begin{array}{llll}8 & 0 & 0 \\ 4 & 0 & 0 \\ 2 & 0 & 0 \\ 1 & 0 & 0 \\ 0,5 & 0 & 0 \\ 0,25 & 0 & 0 \\ \cdots \\ 4 & 2 & 0 \\ 2 & 1 & 0 \\ 1 & 0,5 & 0 \\ 0,5 & 0,25 & 0 \\ 0,25 & 0,125 & 0 \\ 0,125 & 0,0625 & 0 \\ \cdots & \cdots \\ 1 & 1 & 0 \\ 2 & 0,5 & 0 \\ 1 & 0,25 & 0 \\ 0,5 & 0,125 & 0 \\ 0,25 & 0,0625 & 0 \\ 0,125 & 0,03125 & 0\end{array}||$

Step 5. As the last column of $S(3,3)$ is zero, we calculate

$$
A_{1}(2)=\left[\begin{array}{ll}
0,5 & 0,25 \\
1 & 0
\end{array}\right], \quad b_{1}^{T}(2)=\left[\begin{array}{ll}
1 & 0
\end{array}\right], \quad c_{1}(2)=\left[\begin{array}{ll}
8 & 0
\end{array}\right] .
$$

Step 6. As $I N D=1$, we go to Step 7 .

Step 7. $I V=2, M=2$.

Step 8. As $I V>J V, J V=2, M=3$.

Step 9. Applying the factorization algorithm 2 on $V_{22}^{(3)}$ gives

$$
\left[\begin{array}{llll|llll}
4 & 4 & 2 & 2 & 2 & 2 & 1 & 1 \\
2 & 2 & 1 & 1 & 1 & 1 & 0,5 & 0,5
\end{array}\right]=\left[\begin{array}{ll}
1 & \\
0,5 & 1
\end{array}\right]\left[\begin{array}{llll|llll}
4 & 4 & 2 & 2 & 2 & 2 & 1 & 1 \\
0 & 0 & 0 & 0 & 0 & 0 & 0 & 0
\end{array}\right] .
$$

Step 10. As the last row of $Q(2,2)$ is zero, we calculate $A_{4}(1)=0,5, b_{2}(1)=4, c_{2}(1)=1$. Step 11. As $N>M, J V=3, M=4$. Applying the factorization algorithm 2 on $V_{2,3}^{(4)}$ gives

$$
\left[\begin{array}{lllll|lllll|lllll}
4 & 4 & 2 & 2 & 1,5 & 2 & 2 & 1 & 1 & 0,75 & 1 & 1 & 0,5 & 0,5 & 0,375 \\
2 & 2 & 1 & 1 & 0,75 & 1 & 1 & 0,5 & 0,5 & 0,375 & 0,5 & 0,5 & 0,25 & 0,25 & 0,1875
\end{array}\right]=
$$




$$
=\left[\begin{array}{ll}
1 & 1 \\
0,5 & 1
\end{array}\right]\left[\begin{array}{lllll|lllll|lllll}
4 & 4 & 2 & 2 & 1,5 & 2 & 2 & 1 & 1 & 0,75 & 1 & 1 & 0,5 & 0,5 & 0,375 \\
0 & 0 & 0 & 0 & 0 & 0 & 0 & 0 & 0 & 0 & 0 & 0 & 0 & 0 & 0
\end{array}\right] .
$$

Step 13. As the last row of $Q(2,3)$ is zero, we go to Step 11.

Step 11. As $N>M, J V=4, \quad M=5$. Applying the factorization algorithm 2 on $V_{2,4}^{(5)}$ gives

$$
\left[\begin{array}{llllll|llllll}
4 & 4 & 2 & 2 & 1,5 & 1,25 & 2 & 2 & 1 & 1 & 0,75 & 0,625 \\
2 & 2 & 1 & 1 & 0,75 & 0,625 & 1 & 1 & 0,5 & 0,5 & 0,375 & 0,3125
\end{array} \mid\right.
$$

$\left.\begin{array}{llllll|llllll}1 & 1 & 0,5 & 0,5 & 0,375 & 0,3125 & 0,5 & 0,5 & 0,25 & 0,25 & 0,1875 & 0,15625 \\ 0,5 & 0,5 & 0,25 & 0,25 & 0,1875 & 0,15625 & 0,25 & 0,25 & 0,125 & 0,125 & 0,09375 & 0,078125\end{array}\right]=$

$$
\begin{aligned}
& =\left[\begin{array}{ll}
\mathbf{4} & \\
0,5 & 1
\end{array}\right]\left[\begin{array}{llllll|llllll}
4 & 4 & 2 & 2 & 1,5 & 1,25 & 2 & 2 & 1 & 1 & 0,75 & 0,625 \\
0 & 0 & 0 & 0 & 0 & 0 & 0 & 0 & 0 & 0 & 0 & 0
\end{array} \mid\right. \\
& \left.\begin{array}{llllll|llllll}
1 & 1 & 0,5 & 0,5 & 0,375 & 0,3125 & 0,5 & 0,5 & 0,25 & 0,25 & 0,1875 & 0,15625 \\
0 & 0 & 0 & 0 & 0 & 0 & 0 & 0 & 0 & 0 & 0 & 0
\end{array}\right] .
\end{aligned}
$$

Step 13. As the last row of $Q(2,4)$ is zero, we go to Siep 11.

Step 11. As $N=M$, we calculate $A_{3}(1,2)=\left[\begin{array}{ll}4 & 0\end{array}\right]$.

Step. 14. Let us suppose we do not want to continue. The calculated realization is a minimal realization of the sequence $\left\{W_{1}, \ldots, W_{5}\right\}$.

\section{REF E R E N E S}

1. Hinamoto, T. IEEE Trans. Circuits and Syst., 27, № 1, 36-44 (1980).

2. Hinamoto, $T$. IEEE Trans. Circuits and Syst., 28, № 4, 345-347 (1981)

3. Hinamoto, T., Fairman, F. W. IEEE Trans. Acoust., Speech, and Signal Process, 29, 스 4, 846-853 (1981)

4. Mitra, S. K., Sagar, A. D., Pendergrass, N. A. IEEE Trans. Circuits and Syst. 22, № 3, 177-184, (1975).

5. Fornasini, E., Marchesini, G. IEEE Trans. Automat. Contr, 21, № 4, 484-492 (1976)

6. Kung, S.-Y., Lévy, B. C., Morf, M., Kailath, T. Proc. IEFE, 65, № 6, 945-961 (1977).

7. Eising, R. IEEE Trans. Automat. Contr., 23, № 5, 793-799 (1978)

8. Fornasini, E. IEEE Trans. Circuits and Syst., 25, № 5, 290-299 (1978).

9. Fornasini, E., Marchesini, G. IEEE Trans. Pattern Anal. and Machine Intelligence, 2, № 2. 172-176 (1980).

10. Котта Ю. Р. В кн.: Тез. докл. Всесоюзной науч.-техн. конф. «Адаптивные роботы $-82 »$. M., $1982,80-81$.

11. Fornasini, E., Marchesini, G. In: Prepr. of IFAC 8th Congress. Kyoto, 11, 1981, $147-153$.

12. Rissanen, J. SIAM J. Contr., 9, № 3, 420-430 (1971).

Academy of Sciences of the Estonian SSR, Institute of Cybernetics

Received June 9, 1983

\section{Olle KOTTA}

\section{REKURSIIVNE ALGORITM KAHEDIMENSIOONILISTE LINEAARSETE SUSTEEMIDE REALISEERIMISEKS}

Artiklis on vaadeldud kahedimensioonilise lineaarse eraldatava ülekandefunktsiooniga dünaamilise süsteemi olekumudeli leidmist süsteemi välise kirjelduse põhjal ning esitatud ja pōhjendatud algoritm minimaalse osalise realisatsiooni saamiseks. Nimetatud algoritm kujutab endast rekursiivset protsessi, mis uute vaatlustulemuste saamisel täpsustab realisatsiooni. 


\section{РЕКУРСИВНЫИ АЛГОРИТМ РЕАЛИЗАЦИИ ДВУМЕРНЫХ ЛИНЕИНЫХ СИСТЕМ}

Рассматривается задача идентификации внутреннего описания двумерной (2-D) линейной динамической системы с отделимым знаменателем передаточной функции по ее внешнему поведению. Внешнее описание задано с помощью двумерных марковских параметров. Внутреннее описание ищется в виде уравнений состояния (модель Роессера). Предлагается и обосновывается алгоритм минимальной частичной реализации. Он представляет собой рекуррентный процесс, в котором реализация уточняется по мере удлинения последовательности двумерных марковских параметров, в то время как в существующих алгоритмах решение получается лишь для фиксированного конечного набора значений параметров. В основе алгоритма лежит специального вида разложение горизонтальной и вертикальной ганкелевых матриц. Предложенный алгоритм является обобщением алгоритма рекурсивной реализации одномерных (1-D) систем. 